\title{
PRODUÇÃO TEXTUAL EM GRUPO: UMA PROPOSTA DE PESQUISA ACADÊMICA
}

\author{
LONDRINA/PR MAIO/2018
}

\author{
Mariana da Silva Nogueira Ribeiro - UNOPAR - mariana.snogueira@kroton.com.br \\ Renata Karoline Fernandes - UNOPAR - Renata.karoline@kroton.com.br \\ Diego Fogaça Carvalho - UNOPAR - diego.fogaca@kroton.com.br \\ Patrícia Beneti de Oliveira - UNOPAR - patriciabeneti@gmail.com \\ Helenara Regina Sampaio - UNOPAR - helenara@kroton.com.br \\ Adriana Giarola Ferraz Figueiredo - UNOPAR - adriana.gfigueiredo@unopar.br
}

\author{
Tipo: Relato de Experiência Inovadora (EI) \\ Categoria: Pesquisa e Avaliação \\ Setor Educacional: EDUCAÇÃO SUPERIOR
}

\begin{abstract}
RESUMO
A Educação a Distância (EaD), modalidade de educação mediada a partir da utilização de tecnologias de informação e comunicação (TIC), com professores, tutores e alunos desenvolvendo atividades educativas em lugares ou tempos adversos, está ganhando cada vez mais espaço no cenário atual. Com objetivo de apresentar uma das atividades desenvolvidas no curso de Licenciatura em Matemática da Universidade Pitágoras Unopar - UNOPAR, na modalidade EaD, este relato de experiência descreve a proposta da Produção Textual em Grupo (PTG), atividade avaliativa desenvolvida por todos os estudantes e como esta foi abordada para que se configurasse numa pesquisa acadêmica.
\end{abstract}

Palavras-chave: Educação a Distância. Pesquisa acadêmica. Iniciação científica.

\section{AGRADECIMENTOS}

AGRADECEMOS À EQUIPE DE DOCENTES DO CURSO DE LICENCIATURA EM MATEMÁTICA DA UNOPAR E ANHANGUERA. 


\section{INTRODUÇÃO}

A EAD, a partir do século XX, vem se destacando no campo educacional. Segundo o Ministério da Educação (MEC), esta é a modalidade de ensino que mais cresceu no país na última década. De acordo com os dados do Instituto Nacional de Estudos e Pesquisas Educacionais Anísio Teixeira (INEP) a participação da EaD em 2006 era de $4,2 \%$, do total de matrículas em cursos de graduação e aumentou sua participação em 2016 para $18,6 \%$.

Os números corroboram com a pesquisa realizada pela Associação Brasileira de Ensino a Distância (ABED), publicada em 2017 que indica em nível acadêmico aproximadamente 561.667 matriculados em cursos regulamentados totalmente a distância e 217.175 matriculados em cursos regulamentados semipresenciais.

Para Ribeiro (2011), tal crescimento da EaD se deve à acessibilidade de ensino a todos, assim como também o custo reduzido e flexibilidade no tempo. Mediada pelas possibilidades decorrentes da utilização TIC acredita-se que, a EaD seja uma forma para democratizar o acesso ao conhecimento e de expandir oportunidades a todos.

Quando se trata da EaD apoiada por TIC, ou seja, realizada em um ambiente virtual de aprendizagem, que "possibilita a comunicação síncrona e assíncrona de um para um, de um para todos e principalmente de todos para todos" (LEITE, 2006, p. 141), a interação entre alunos, professor e tutor passa a ser mediado pelos recursos tecnológicos disponíveis, de modo que as metodologias de ensino sejam diferenciadas e que proporcionem atividades distintas, assim como também um processo para a iniciação científica.

Considerando o foco do trabalho o desenvolvimento da pesquisa acadêmica, como uma das propostas de trabalho científico, no curso de Licenciatura em Matemática da UNOPAR, na modalidade EaD, é desenvolvida a Produção Textual em Grupo (PTG), em que os estudantes realizam uma pesquisa acadêmica em grupo, propiciando a colaboração, o trabalho em equipe e a interdisciplinaridade com situações do dia a dia.

Para tanto, este Relato de Experiência, com caráter de uma pesquisa qualitativa com característica descritiva, tem como objetivo descrever a metodologia utilizada nestas PTG, assim como também algumas pesquisas desenvolvidas no decorrer do curso, apresentando como essas se configuram numa pesquisa acadêmica. 
As Diretrizes Curriculares Nacionais - DCN (BRASIL, 2002) para o curso de Licenciatura em Matemática orientam que ações sejam desenvolvidas a fim de propiciar aos estudantes uma complementação da postura de estudante, a de pesquisador.

De acordo com as DCN (BRASIL, 2002) para o curso de Licenciatura em Matemática, no que tange às competências e às habilidades próprias do educador matemático, a formação inicial deve possibilitar que o licenciando em Matemática seja capaz de elaborar propostas de ensino-aprendizagem de Matemática para a Educação Básica, como analisar, selecionar e produzir materiais didáticos, além de inquirir, criticamente, propostas curriculares de Matemática para a Educação Básica. Assim, é preciso que os currículos sejam elaborados de modo que os educandos tornem-se capacitados para se expressar na escrita e oralmente, com clareza e com precisão.

É na formação inicial que os estudantes do curso de Licenciatura em Matemática da Unopar EaD estabelecem seus primeiros contatos com as atividades de pesquisa relacionadas ao ensino e à aprendizagem de Matemática. Um dos objetivos do curso é inserir o aluno em atividades de pesquisa sobre diferentes temas, como forma de ampliar o conhecimento matemático e buscar alternativas metodológicas para o trabalho docente (PPC, 2017, p.22).

O estudante da EaD deve ter algumas características, entre elas, destaca-se a autonomia. Essa característica é necessária para a organização do tempo para leituras dos materiais didáticos e para a realização de pesquisas sobre os conteúdos no curso, articulando os pilares ensino, pesquisa e extensão, mediada pelas TIC.

O uso das TIC está criando um novo tipo de ambiente, e o cenário do ensino e da aprendizagem também tem se modificado; é preciso, portanto, "[...] desenvolver diferentes abordagens para o seu aprendizado - de maneira que ele se torne capaz de 'aprender a aprender' com as diferentes situações que enfrentará na vida, não apenas em uma instituição de ensino formal". (MOORE; KEARSLEY, 2008, p. 84). O ato de aprender é um processo que está vinculado ao tipo de inteligência, à dedicação aos estudos e à atividade profissional.

$\mathrm{Na} \mathrm{EaD,} \mathrm{o} \mathrm{grau} \mathrm{de} \mathrm{atividades} \mathrm{aumenta} \mathrm{consideravelmente,} \mathrm{tanto} \mathrm{para} \mathrm{professores}$ quanto para estudantes. Estes últimos, ao iniciar o Ensino Superior à Distância, frequentemente não compreendem que precisam assumir uma postura proativa frente ao curso, ou seja, ter autonomia para conduzir bem sua aprendizagem na disciplina. Conforme Moore e Kearsley (2008, p. 246), precisamos da "[...] capacidade do aluno para construir significado e a disposição necessária para iniciar e persistir em uma 
iniciativa de aprendizagem".

Considerando que, no Ensino Superior, o foco das instituições deve estar no desenvolvimento do conhecimento e que o aluno deve ser estimulado a produzir trabalhos científicos, com embasamento e com propriedade, o contexto acadêmico deve estar ligado, também, à prática da pesquisa, que é uma condição possível de aliar a teoria apreendida no contexto da sala de aula à prática, estabelecendo um caminho mais profícuo na aquisição das competências necessárias para o exercício profissional almejado.

Diante disso, a iniciação cientifica pode ser um diferencial, visto que estabelece métodos e regras, como a possibilidade de uma leitura analítica, que não se resume, simplesmente, na superficialidade ou em um comportamento mecânico diante da pesquisa e do contato com o texto, É preciso conduzir o aluno a uma leitura com objetivos, que vise à circunstância da produção, provocando uma determinada reação, a construção do conhecimento, pois a pesquisa no Ensino Superior precisa estabelecer um norte para o aluno, ou seja, facilitar, incentivar e incrementar a prática educativa.

Além disso, é preciso saber dosar essa prática e inseri-la, de fato, no contexto acadêmico, pois só assim, quando pesquisa e ensino caminharem juntos, o conhecimento acontecerá integralmente, com ganhos notórios na Educação, pois, conforme Pedro Demo,

Sem pesquisa não há ensino. A ausência de pesquisa degrada o ensino a patamares típicos da reprodução imitativa. [...] Se a pesquisa é a razão do ensino, vale o reverso: o ensino é a razão da pesquisa, se não quisermos alimentar a ciência como prepotência a serviço de interesses particulares. Transmitir conhecimento deve fazer parte do mesmo ato de pesquisa, seja sob a ótica de dar aulas, seja como socialização do saber, seja como divulgação socialmente relevante (2005, p. 51-52).

Assim, as instituições de Ensino Superior, amparadas pelos aspectos legais das Diretrizes Curriculares Nacionais para os cursos de Licenciatura, nesse caso, Licenciatura em Matemática, devem destacar elementos de fundamentação conceitual da pesquisa e de toda a sua constituição, isso porque, para além da obrigatoriedade legal, há uma questão pedagógica, que corrobora a necessidade de se pensar no contexto professor/aluno/teoria/prática como um cenário de construção do conhecimento, em que a interação com o outro, o exercício da pesquisa, da leitura e do desenvolvimento do conhecimento, exemplificam o que afirmou Paulo Freire: "não há ensino sem pesquisa e pesquisa sem ensino" (2014, p. 30). 


\section{PRODUÇÃO TEXTUAL EM GRUPO}

No curso de Licenciatura em Matemática da UNOPAR, na modalidade EaD, uma das atividades que o aluno desenvolve é chamada de PTG, que está relacionada aos conteúdos das disciplinas do semestre que o aluno está cursando. Conforme os documentos orientadores do curso "Guia de Percurso", o objetivo desta atividade é estabelecer a relação entre a teoria e a prática e a aplicação dos conteúdos à realidade local e regional dos alunos participantes do curso.

Inicialmente, a PTG do curso de Licenciatura em Matemática era elaborada a partir de um estudo de caso em que o estudante deveria realizar sua análise se posteriormente sua resposta a respeito dos itens questionados. A partir do primeiro semestre de 2017, 0 trabalho passou a constituir-se como uma oportunidade para os alunos aplicarem os conhecimentos adquiridos ao longo do semestre, nas diferentes disciplinas cursadas, visando a análise de situações passíveis de vivência em sua futura carreira profissional, refletindo teoricamente sobre elas e delineando ações para a solução de problemas e apresentando o resultado final de suas análises por meio de uma estrutura que se aproxima da estrutura de um artigo científico.

A PTG deve ser realizada em grupo durante o semestre, contemplando a submissão de um trabalho textual no seu ambiente virtual de aprendizagem (AVA). O trabalho final é avaliado e conceituado por meio de critérios estabelecidos pelos professores do semestre. Para elaboração da proposta, os professores de cada disciplina se reúnem no início de cada semestre e elaboram o manual da PTG de tal forma que, as atividades são interdisciplinares e podem ser aplicadas em situações do dia a dia do aluno. Abaixo, o quadro 1 apresenta as etapas que os professores percorrem para construção da PTG:

Quadro 1: Etapas para elaboração da proposta para a PTG

\begin{tabular}{|l|l|}
\hline ETAPAS & DESCRIÇÃO \\
\hline Primeira & Escolha do eixo integrador e/ou tema. \\
\hline Segunda & Contextualização para situação geradora de aprendizagem \\
\hline Terceira & Escolha da situação geradora de aprendizagem \\
\hline Quarta & $\begin{array}{l}\text { Descrição de tarefas de cada disciplina para resolução da situação-problema } \\
\text { geral. }\end{array}$ \\
\hline Quinta & Modelo final do trabalho de acordo com as normas da ABNT. \\
\hline
\end{tabular}

Fonte: elaborado pelos autores. 
A partir de um levantamento, foi possível identificar quais temas já foram propostos nos semestres do curso de Licenciatura em Matemática da Unopar, na modalidade EaD.Fonte: elaborado pelos autores.

Quadro 2: Temáticas propostas - PTG

\begin{tabular}{|c|c|}
\hline TEMÁTICAS & DISCIPLINAS NORTEADORAS \\
\hline $\begin{array}{l}\text { omunicação na sala } \\
\text { de aula }\end{array}$ & $\begin{array}{c}\text { Álgebra Linear e Vetorial; Estágio Curricular Obrigatório II; Metodologia } \\
\text { do Ensino da Matemática; Seminário da Prática V; Tecnologias no } \\
\text { Ensino da Matemática. }\end{array}$ \\
\hline $\begin{array}{l}\text { Educação Ambiental } \\
\text { (EA) na Educação } \\
\text { Básica }\end{array}$ & $\begin{array}{l}\text { Ética, Política e Cidadania; Políticas Públicas na Educação Básica; } \\
\text { Educação e Diversidade; Psicologia da Educação e da Aprendizagem; } \\
\text { Práticas Pedagógicas: gestão da aprendizagem; }\end{array}$ \\
\hline $\begin{array}{l}\text { Produção do } \\
\text { conhecimento } \\
\text { matemático }\end{array}$ & $\begin{array}{c}\text { Análise Matemática; Cálculo Numérico; Educação Financeira; Seminário } \\
\text { da Prática VII - Tópicos Especiais; Projeto de Ensino. }\end{array}$ \\
\hline $\begin{array}{l}\text { Pesquisa sobre a } \\
\text { história da lógica } \\
\text { matemática }\end{array}$ & $\begin{array}{l}\text { Lógica Matemática; Estatística e Probabilidade; História da Matemática; } \\
\text { Seminário da Prática IV e Estágio Curricular Obrigatório I. }\end{array}$ \\
\hline $\begin{array}{l}\text { Desenvolvimento de } \\
\text { um modelo } \\
\text { matemático }\end{array}$ & $\begin{array}{l}\text { Cálculo Diferencial e Integral; Estruturas Algébricas; Modelagem } \\
\text { Matemática e Seminário da Prática VI. }\end{array}$ \\
\hline $\begin{array}{c}\text { Interpolação } \\
\text { polinomial na } \\
\text { resolução de um } \\
\text { problema }\end{array}$ & $\begin{array}{l}\text { Educação Financeira; Cálculo Numérico; Análise Matemática; Projeto de } \\
\text { Ensino; Seminário da Prática VII - Tópicos especiais. }\end{array}$ \\
\hline $\begin{array}{l}\text { Metodologias de } \\
\text { Ensino }\end{array}$ & $\begin{array}{c}\text { Tecnologias no Ensino da Matemática; Álgebra Linear e Vetorial; } \\
\text { Metodologia do Ensino da Matemática; Estágio Curricular Obrigatório II; } \\
\text { Seminário da Prática V. }\end{array}$ \\
\hline $\begin{array}{l}\text { A doação de sangue } \\
\text { no Brasil }\end{array}$ & $\begin{array}{l}\text { Modelagem Matemática; Cálculo Diferencial e Integral e Estruturas } \\
\text { Algébricas; Estágio Curricular Obrigatório III e Seminário da Prática VI. }\end{array}$ \\
\hline
\end{tabular}

Fonte: elaborado pelos autores.

De acordo com a estrutura proposta pelos professores, o trabalho final entregue pelos alunos, tem formato de uma pesquisa acadêmica. Segundo Demo (2001), a pesquisa acadêmica está misturada à prática de ensino e deve exercer a atividade educativa formal, ou seja, uma informação adicional que agregamos à prática de ensino, assim, a 
atividade desenvolvida pelos estudantes assemelha-se a atividades desenvolvidas por estudantes que participam de pesquisas de Iniciação Científica.

Para Fonte (2004), uma pesquisa acadêmica consiste em um processo de investigação, recorrendo a procedimentos científicos para encontrar respostas para uma situaçãoproblema, sendo necessário avaliar o problema proposto e verificar se o trabalho constitui no que irá produzir em resultados novos e relevantes para o interesse social.

Uma das propostas citadas no quadro 2, teve como tema a "A doação de sangue no Brasil", com as seguintes disciplinas norteadoras: Modelagem Matemática, Cálculo Diferencial e Integral e Estruturas Algébricas, Estágio Curricular Obrigatório III e Seminário da Prática VI.

Para contextualização da Situação Geradora de Aprendizagem (SGA) os professores selecionaram um texto informativo sobre características e dados estatísticos sobre doação de sangue no Brasil. Em seguida foi proposta a SGA, que tinha como objetivo construir e analisar um modelo que representasse o perfil de acordo com a idade dos doares de sangue no Brasil.

Para isso, foi proposto no primeiro momento, questionamentos relacionados aos conteúdos desenvolvidos no decorrer do semestre, com intuito de proporcionar reflexões para a elaboração do modelo. Alguns questionamentos no primeiro momento foi: O que acontece com o percentual de doadores dos 18 aos 35 anos? Represente esses dados em um gráfico. Esse comportamento é característico de qual tipo de função?

Neste momento, evidencia-se o início de uma pesquisa acadêmica, no qual, de acordo com Castro (2011), como em qualquer pesquisa, a primeira e mais importante decisão no planejamento da revisão sistemática é a determinação do foco, ou seja, a pergunta.

Num segundo momento os alunos tinham que construir o modelo que representa os dados apresentados na tabela do primeiro momento. Durante o desenvolvimento do modelo faz-se necessário que o aluno busque em referenciais teóricos a caracterização do problema, justificativa, objetivos, delimitação do problema, assim como os procedimentos metodológicos, para encontrar um modelo matemático. Todas essas etapas perfazem para a estrutura de uma pesquisa acadêmica, decorrendo somente das considerações finais, quais estão propostas no próximo momento.

Assim, após a construção do modelo, referente ao segundo momento, os alunos devem realizar uma análise matemática do mesmo, respondendo as seguintes questões e 
considerando o domínio da função encontrada como sendo o dos $\mathrm{R}$ (conjunto dos números reais). Qual a derivada da função encontrada? Qual o significado dessa derivada? Qual o significado dessa segunda derivada? A função possui ponto de máximo ou de mínimo? Identifique o ponto de máximo ou de mínimo se houver.

Logo, a partir da estrutura e orientações propostas pelos professores para a elaboração da PTG, o trabalho final dos alunos do curso de Licenciatura em Matemática da Unopar, se configura numa produção de pesquisa acadêmica, de acordo com as normas da ABNT, e neste caso em específico, na EaD. Assim, por meio do desenvolvimento da PTG, permite-se que todos os estudantes do curso de Licenciatura em Matemática, tenham em sua graduação experiências com a produção científica e com a escrita formal, característica de artigos científicos.

\section{CONCLUSÃO}

As Instituições de Ensino Superior, amparadas pelos aspectos legais das Diretrizes Curriculares Nacionais para os cursos de licenciatura em Matemática, destaca a importância em desenvolver a pesquisa científica no decorrer da formação acadêmica, uma vez que, existe uma questão pedagógica, que se preocupa com a necessidade de se pensar no contexto professor/aluno/teoria/prática como um cenário de construção do conhecimento.

A partir dos procedimentos propostos pelos professores para construção da PTG, foi possível identificar que esta, se configura como uma pesquisa acadêmica, pois ao desenvolver as etapas para construção da produção textual, o aluno percorre todas as fases que se julgam obrigatórias para elaboração de uma pesquisa científica.

Neste sentindo, também é importante destacar a autonomia do aluno em seu processo de aprendizagem num curso de modalidade EaD, ou seja, ser protagonista de seu ensino com ênfase na pesquisa acadêmica, bem como compartilhar suas compreensões e discutir as dúvidas sobre um conceito em grupo e ter a possibilidade de desenvolver uma pesquisa científica.

\section{REFERÊNCIAS}

ABED. Relatório Analítico da Aprendizagem a Distância no Brasil. Censo EaD.br. 2016. Disponível em: http://abed.org.br/censoEaD2016/Censo_EAD_2016_portugues.pdf. Acesso em: 23 abr. 2018. 
ALENCASTRO, M. SOCZEK, M. Pesquisa acadêmica em instituições de ensino superior particulares: desafios e perspectivas. Revista Intersaberes, vol.7, n.13, p. 46 - 66, jan. - jun. 2012.

BRASIL. Instituto Nacional de Estudos e Pesquisas Educacionais Anísio Teixeira (INEP). Censo da Educação de Ensino Superior 2016. Disponível em: http://download.inep.gov.br/educacao_superior/censo_superior/documentos/2016/notas sobre_o_censo_da_educacao_superior_2016.pdf. Acesso em: 23 abr. 2018.

BRASIL. Parecer CNE/CES 1.302/2001. Diretrizes Curriculares Nacionais para os Cursos de Matemática, Bacharelado e Licenciatura. DCN. Diário Oficial da União, Brasília, D.F., 5 de mar. de 2002. Seção 1, p. 15. Disponível em: http://portal.mec.gov.br/cne/arquivos/pdf/CES13022.pdf. Acesso em 25 abr. 2018.

CASTRO, A. A. Formulação da pergunta de pesquisa. São Paulo. 2001. Disponível em:

http://www.usinadepesquisa.com/metodologia/wpcontent/uploads/2010/08/lv5_rsl04.pdf. Acesso em 24 abr. 2018.

DEMO, P. Pesquisa: princípio científico e educativo. 8. ed. São Paulo: Cortez, 2005.

FONTE, N.N. Pesquisa científica: o que é e como se faz. 2004.

FREIRE, P. Pedagogia da autonomia: saberes necessários à prática educativa. 49. ed. Rio de Janeiro: paz e Terra, 2014.

LEITE, L. Teoria da Distância Transacional e o processo de avaliação da aprendizagem em EaD. In: SILVA, Marco; SANTOS, Edméa (orgs.). Avaliação da aprendizagem em educação online, p. 141 a 152. São Paulo: Edições Loyola, 2006.

NASCIMENTO, F.; CARNIELLI, B. L. Educação a distância no ensino superior: expansão com qualidade? Etd - Educação Temática Digital. Campinas, v. 9, n. 1, p. 84-98, dez. 2007.

MAIA, C.; MATTAR, J. ABC da EAD: a educação a distância hoje. São Paulo: Pearson Prentice Hall, 2007.

MOORE, M.; KEARSLEY, G. Educação a distância: uma visão integrada. São Paulo: Cengage Learning, 2008. 
RIBEIRO, M. Garcia. Educação a Distância: um desafio na formação de professores. 2011. Dissertação de Mestrado - Universidade Federal do Paraná, Curitiba.

UNOPAR EAD. Guia de Percurso do curso de Licenciatura em Matemática ingressantes a partir de 2017/1. Londrina, 2017.

UNOPAR EAD. Projeto Pedagógico do curso de licenciatura em Matemática. Londrina, 2017. 